\title{
CALCULATION METHODOLOGY FOR DESIGN OF CONNECTING ROD CONSIDERING FATIGUE STRESSES IN IC ENGINE
}

Sachin S Gandhul

Engineering Research Centre

Tata Technologies Ltd. Pune, Maharashtra, India.
Abstract - In this Literature, design and structural calculations of connecting rod of IC engine has been performed. Design point of view, connecting rod is most critical part as it the only part which converts reciprocating forces into rotating forces. It is subjected to complex loading of compression and tensile under cyclic process. Therefore, the design calculations are done considering the fatigue life of connecting rod. This work computes, the required strength and size in the critical areas of connecting rod. The calculation methodology is also verified with existing connecting rods of three different engine categories, like small petrol engine, SUV diesel engine and heavy commercial Engine.

Keywords - Connecting rod calculations, Fatigue, Endurance, Con rod, I C Engine

\section{INTRODUCTION}

The connecting rod calculations is the critical topic of design and research due to its motion and complex loading. Before detailed FEA analysis it is necessary to find out the dimensions by calculations to build the primary 3D model of connecting rod. So it becomes necessary to calculate the forces \& there loading pattern acting on connecting rod. Normally it is made of $\mathrm{H}$ section. $\mathrm{H}$ Section is having high inertia and less weight compared to circle or rectangular sections. $\mathrm{H}$ section is also better in sustaining high buckling and bending stresses. [1][3] The connecting rod is subjected to complex cyclic forces. Which includes tensile stress due to inertia forces \& compressive force due to combustion.[2]. Here infinity life of connecting rod is considered while laying down this methodology. Commonly material used are aluminum of steel alloys, such as 25CrMo4, 42CrMo4, C70, AISI 1070, etc.

This calculation can be used to optimize/weight reduction of existing or for design of new connecting rod.

\section{Proposed Algorithm}

This approach suggests improved method of calculations of connecting rod of internal combustion engine. Stress pattern of cyclic loads on connecting rod is already identified as fluctuating [2]. Load variation w.r.t crank angle [4][7], Max

\author{
Vijay Surywanshi, Ajeet Kumar Shriwastava, \\ Engineering Research Centre \\ Tata Technologies Ltd. Pune, Maharashtra, India
}

Compressive and maximum tensile loads considering p-theta diagram [4][7], endurance limits, buckling, flexural rigidity etc are considered in proper maner to get more accurate results. Following algorithm is used to laid down for the calculation / design methodology:

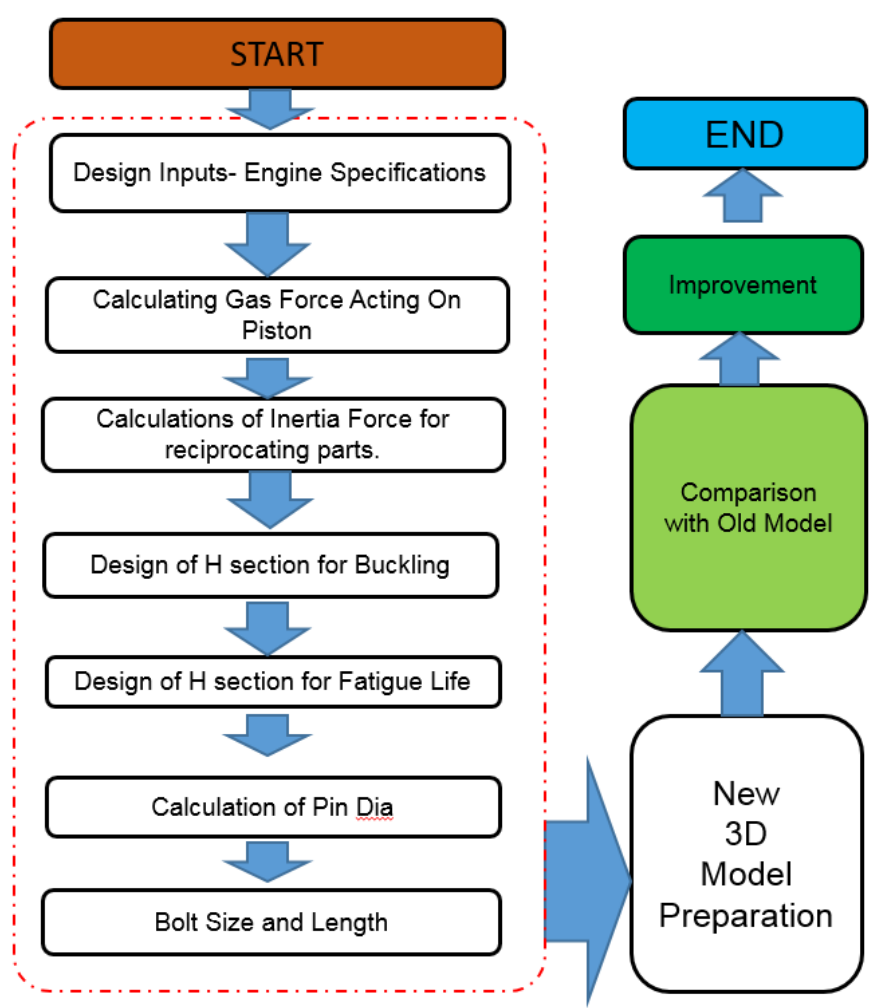

Fig. 1. Flow chart for Design of Connecting Rod. 


\section{International Journal of Engineering Applied Sciences and Technology, 2020 \\ Vol. 4, Issue 10, ISSN No. 2455-2143, Pages 116-121 \\ Published Online February 2020 in IJEAST (http://www.ijeast.com)}

\subsection{Engine Specifications:}

Table 1. Required Design Inputs - Engine specifications.

\begin{tabular}{|l|l|l|l|}
\hline S.N & Parameter & Sym & Unit \\
\hline 1 & Engine Capacity & Vs & $\mathrm{cc}$ \\
\hline 2 & Cyl. Bore Diameter & $\mathrm{d}$ & $\mathrm{m}$ \\
\hline 3 & Piston Stroke & $\mathrm{s}$ & $\mathrm{m}$ \\
\hline 4 & Crank Radius & $\mathrm{r}$ & $\mathrm{m}$ \\
\hline 5 & Con rod length & $\mathrm{l}$ & $\mathrm{m}$ \\
\hline 6 & Max. Engine Speed & $\mathrm{V}$ & $\mathrm{rpm}$ \\
\hline 7 & Obliquity Ratio & $\mathrm{n}$ & - \\
\hline 8 & Total Mass of connecting rod. & $\mathrm{Mc}$ & $\mathrm{Kg}$ \\
\hline 9 & Mass of Piston Assy \& Pin & $\mathrm{Mp}$ & $\mathrm{Kg}$ \\
\hline 10 & Max. Combustion Pressure & $\mathrm{Pg}$ & $\mathrm{N} / \mathrm{m} 2$ \\
\hline & & & \multicolumn{1}{l}{} \\
\hline
\end{tabular}

\section{Design Inputs - Material Specifications:}

Table 2. Material Properties of connecting rod - 42CrMo4

\begin{tabular}{|l|l|l|l|}
\hline S.N & Parameter & Value & Unit \\
\hline 1 & Young's modulus (E) & 200 & $\mathrm{Gpa}$ \\
\hline 2 & Ultimate Tensile Strength (Sut) & 900 & $\mathrm{Mpa}$ \\
\hline 3 & Yield Strength (Syt) & 650 & $\mathrm{Mpa}$ \\
\hline 4 & Compressive/crushing stress $(\sigma c)$ & 650 & $\mathrm{Mpa}$ \\
\hline 5 & Endurance Strength (Se') & 420 & $\mathrm{Mpa}$ \\
\hline 6 & Endurance Bending Strength $\left(\sigma_{\mathrm{eb}}\right)$ & 530 & $\mathrm{Mpa}$ \\
\hline
\end{tabular}

$\mathrm{Se}=$ endurance limit of actual connecting rod.

$\mathrm{Se}=\mathrm{Ka} . \mathrm{Kb} . \mathrm{Kc} . \mathrm{Kd} . \mathrm{Ke} \cdot \mathrm{Kg} \cdot \mathrm{Se}$

$$
\begin{aligned}
& =0.78 \times 1 \times 1 \times 1.02 \times 1 \times 1 \times 420 \\
& =334.152 \mathrm{MPa}
\end{aligned}
$$

Actual connecting rod Specification for endurance:

Table 3. Actual Material Properties of connecting rod -

\begin{tabular}{|l|l|l|l|}
\hline S.N & Parameter & Value & Unit \\
\hline 1 & Endurance Strength (Se) & 334.15 & Mpa \\
\hline 2 & $\begin{array}{l}\text { Endurance Shear Str. (Max shear ) } \\
(\text { Ses })\end{array}$ & 167 & Mpa \\
\hline 3 & $\begin{array}{l}\text { Endurance shear Str (Von mises) } \\
(\text { Ses })\end{array}$ & 193 & Mpa \\
\hline 4 & Endurance Bending Strength $\left(\sigma_{\mathrm{eb}}\right)$ & 422 & Mpa \\
\hline
\end{tabular}

\subsection{Forces on Connecting rod:}

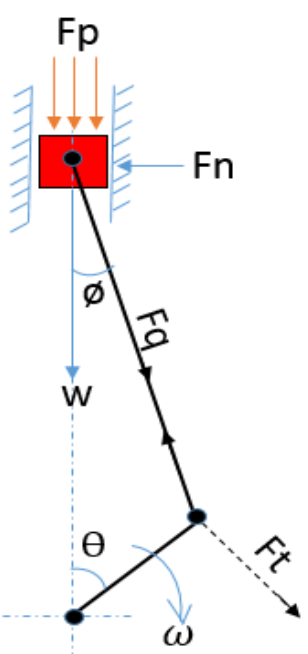

Figure 2. Slider Crank Mechanism for Connecting rod.

Gas Force of Piston Top (Fg):

$$
\mathrm{Fg}=\text { Pg. } A=\operatorname{Pg} \cdot \frac{\pi \mathrm{d}^{2}}{4}
$$

2.2 Inertia force due to reciprocating mass (Fi):

Two mass equivalent system for connecting rod

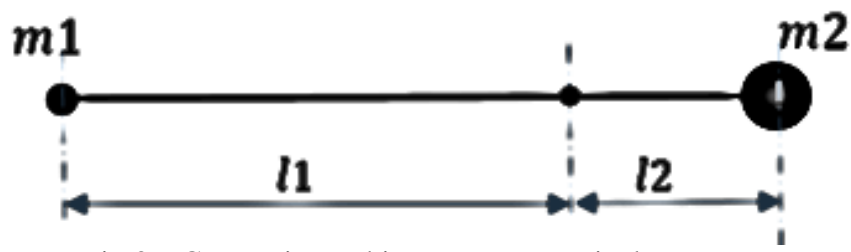

Fig.3 - Connecting rod in Two mass equivalent system.

ll. $m 1=l 2 . m 2$, where $m 1+m 2=m$ and $l 1+l 2=l$

$m 1=\frac{(l-l 1) \cdot(M c-m 1)}{l 1} \quad \& \quad m 2=\frac{(l-l 2) \cdot(M c-m 2)}{l 2}$

$m l=$ Reciprocating mass of connecting rod $=\mathbf{m} \mathbf{1} \mathrm{kg}$.

$M r=$ Total Reciprocating mass $=m l+M p=\mathbf{M r} \mathrm{Kg}$

Piston acceleration $=a=\omega^{2} \cdot r \cdot\left(\cos \theta+\frac{\cos 2 \theta}{n}\right)$.

Piston acceleration will be maximum when piston will be at TDC i.e $\theta$ is zero.

$$
\mathrm{a}=\omega^{2} \cdot r \cdot\left(\cos (0)+\frac{\cos (2 \times 0)}{n}\right) \mathrm{m} / \mathrm{s}^{2}
$$

Inertia/acceleration force due to reciprocating mass,

$$
\mathrm{Fi}=\mathrm{Mr} . \mathrm{a}
$$




\subsection{Force due to weight of reciprocating mass $(w)$ :}

$$
\mathrm{w}=\mathrm{Mr} \cdot \mathrm{g}
$$

Friction force (Ff) between Piston and cylinder wall can be neglected [2], because it is reducing the applied force on connecting rod.

2.4 Net max. Force on piston pin, (Fp:)

$$
\mathrm{Fp}=\mathrm{Fg}-\mathrm{Fi} \pm \mathrm{Ff}+\mathrm{W}
$$

Max. Compressive Force along connecting rod (Fq) can be found out using trigonometric relation between $\theta$ and $\varnothing$ as shown in figure.2.[2]. And Inertia Force (Fi) will act as Maximum Tensile Force along connecting rod. Fq and Fi are the forces which are considered for further calculations.

\section{H section Design:}

$2.5 \mathrm{H}$ section design for buckling of con rod.
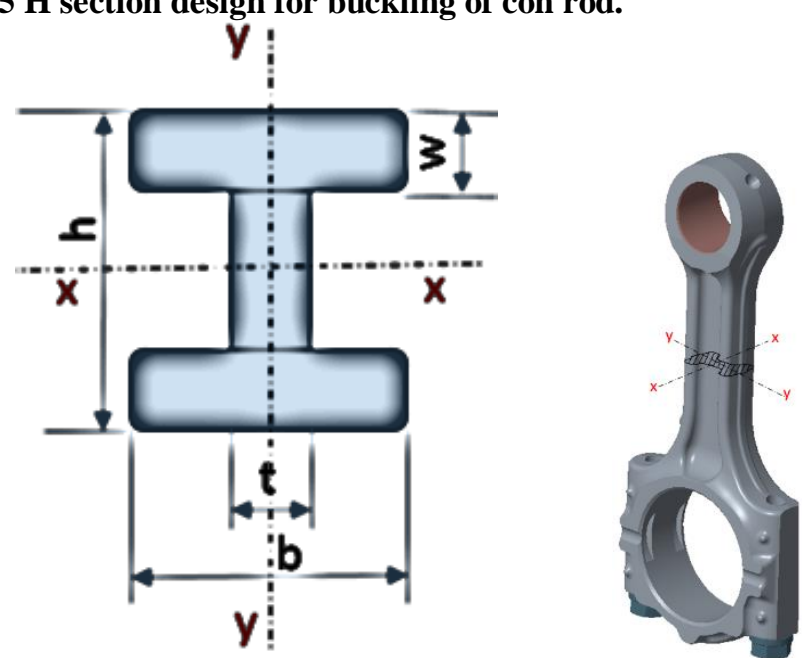

Figure 4 . $\mathrm{H}$ section and of connecting rod.

Assumed or primary dimensions of $\mathrm{H}$ section$\mathrm{b}=$ Width $\mathrm{h}=$ Height $\mathrm{w}=$ Thickness $\mathrm{t}=$ Thickness.

Area of Assumed I section, A = (b x h)-[(b-t) x (h-2w)]

$$
=\mathbf{A ~ m ^ { 2 }}
$$

Effective length of Connecting rod about $\mathrm{xx}, \mathrm{Le}=\boldsymbol{l} \mathrm{mm}$.

Effective length of connecting rod about yy, $\mathrm{Le}=\boldsymbol{l} / \mathbf{2} \mathrm{mm}$.

Moment of Inertia about $\mathrm{xx}, \mathrm{Ixx}=\frac{\mathrm{bxh}^{3}}{12} \mathrm{~mm}^{4}$.

Moment of Inertia about yy, Iyy $=\frac{\mathrm{hxb}^{3}}{12} \mathrm{~mm}^{4}$

Radius of gyration about $\mathrm{xx}, K x x=\sqrt{\frac{I x x}{A}} \mathrm{~mm}$

Radius of gyration about yy, $K y y=\sqrt{\frac{I y y}{A}} \mathrm{~mm}$

Rankine constant for given material, $\mathrm{a}=\frac{\sigma \mathrm{c}}{\pi^{2} \cdot E}=0.000329 \ldots[1]$

Factor of Safety $=2$

\section{Buckling load about $\mathrm{xx}$ axis, Fc:}

$$
F C=\frac{\sigma c x A^{\prime}}{1+a\left(\frac{L e}{K x x}\right)^{2}} X \frac{1}{F O S}
$$

Min. required area of I section to avoid buckling about $\mathrm{X}$ - $\mathrm{X}$ axis.

$$
\mathrm{A}^{\prime}=\frac{\text { Fc.Fos. }\left[1+a\left(\frac{L e}{K x x}\right)^{2}\right]}{\sigma c} \mathrm{~mm}^{2}
$$

Assumed $\mathrm{H}$ section Area A > A', so design is safe in buckling about $\mathrm{xx}$

Buckling load about yy axis, Fc :

Min. required area for I section to avoid buckling about $y-y$ axis.

$$
A^{\prime}=\frac{\text { Fc.Fos. }\left[1+a\left(\frac{L e}{K y y}\right)^{2}\right]}{\sigma c} \mathrm{~mm}^{2}
$$

If assumed $\mathrm{H}$ section Area $\mathrm{A}>\mathrm{A}^{\prime}$, design is safe in buckling about $\mathrm{xx}$

\subsection{Calculation of $\mathrm{H}$ section under axial loading on:}

Considering Fq and Fi through 360 degree, we get resulting forces in fluctuating manner, so let's find out $\sigma_{\max }$ and $\sigma_{\min }$ and then $\sigma_{\mathrm{a}}$ and $\sigma_{\mathrm{m}}$.

$$
\begin{aligned}
& \sigma_{\mathrm{a}}=\frac{\sigma_{\max }-\sigma_{\min }}{2} \mathbf{N} / \mathbf{m m}^{2} \\
& \sigma_{\mathrm{m}}=\frac{\sigma_{\max +} \sigma_{\min }}{2} \mathbf{N} / \mathbf{m m}^{2}
\end{aligned}
$$

Considering modified Goodman Theory, and selecting equation for Goodman line. [3]

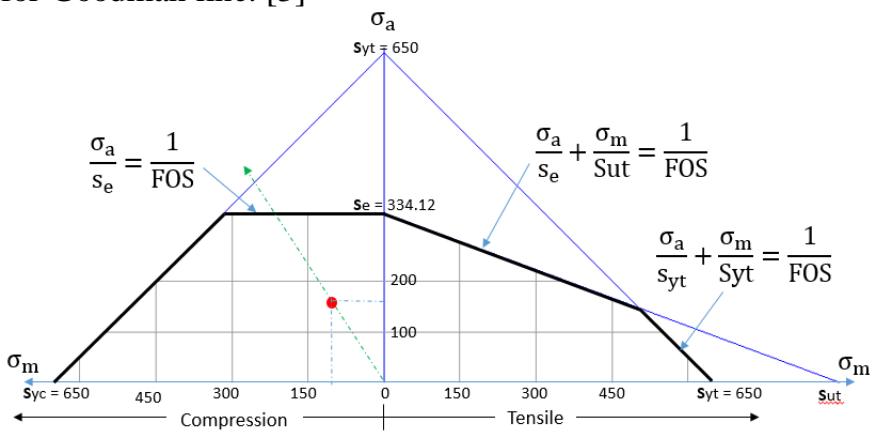

Figure 5. Modified Goodman diagram for 25CrMo4, 45CrMoo4, C70 and equivalent materials.

Equation of suitable line: $\frac{\sigma_{\mathrm{a}}}{\mathrm{s}_{\mathrm{e}}}=\frac{1}{\mathrm{FOS}}$

Rearranging the Goodman Line equation to obtain area:

$$
\frac{\frac{\sigma_{\max }-\sigma_{\min }}{2}}{\mathrm{~s}_{\mathrm{e}}}=\frac{1}{\mathrm{FOS}}
$$




$$
\mathrm{A}^{\prime}=\frac{(F i-(-F q)}{\mathrm{Se} \cdot 2} \cdot F O S \mathbf{m m}^{2}
$$

If assumed I section Area A > A', It is safe for axial loading.

\subsection{Small End / Piston Pin Dia Calculation:}

Table 4. Material Properties of Piston Pin - $16 \mathrm{MnCr}$.

\begin{tabular}{|c|l|r|c|}
\hline S.N & Parameter & Value & Unit \\
\hline 1 & Endurance Strength (Se) & 420 & $\mathrm{Mpa}$ \\
\hline 2 & $\begin{array}{l}\text { Endurance Shear Str (Max shear } \\
\text { stress) (Ses) }\end{array}$ & 210 & $\mathrm{Mpa}$ \\
\hline 3 & $\begin{array}{l}\text { Endurance shear Strength (Von } \\
\text { mises stress) (Ses) }\end{array}$ & 240 & $\mathrm{Mpa}$ \\
\hline 4 & Endurance Bending Strength $\sigma_{\mathrm{eb}}$ ) & 350 & $\mathrm{Mpa}$ \\
\hline
\end{tabular}

In case of Piston pin, lads are completely reversed so Considering S-N curve for infinity life of Pin.[8]

Piston Pin Subjected to double shear stress:

$$
\begin{aligned}
\text { Ses } & =\frac{\mathrm{F}_{\mathrm{P}} \cdot \mathrm{FOS}}{2 \cdot \mathrm{A}} \quad(\text { Ses }=210 \mathrm{Mpa}-\text { max shear theory }) \ldots . . \\
\mathrm{A} & =\frac{\pi\left[\mathrm{d}^{2}-(\mathrm{d}-2 \cdot \mathrm{t})^{2}\right]}{4} \quad(\mathrm{t}=\text { thickness of hollow Pin })
\end{aligned}
$$

Min. required small end ID of connecting rod subjected to shear, $\mathrm{d}=\mathbf{x} \mathbf{~ m m}$.

Piston Pin is subjected to Crushing stress, $\sigma \mathrm{c}:-$ $\sigma c=\mathrm{Se}=\frac{\mathrm{F}_{\mathrm{P}} \cdot \mathrm{FOS}}{l \cdot(d-2 . t)} \quad(l=$ small end width $)$

$$
\mathrm{d}=\mathbf{x}^{\prime} \mathbf{m m}
$$

Min. required small end ID of connecting rod subjected to crushing, $d=\mathbf{x}^{\prime} \mathbf{m m}$.

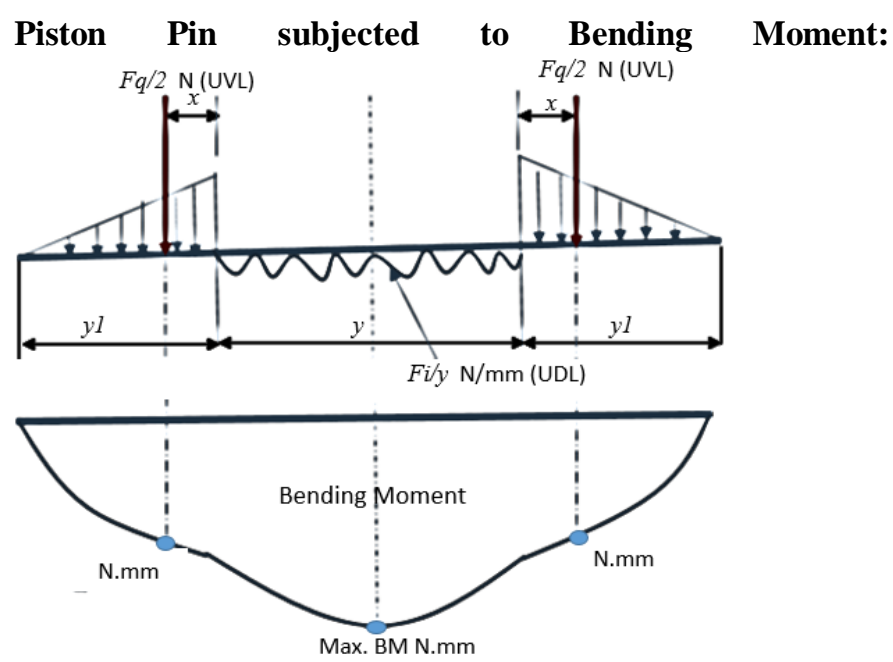

Figure 5. Force representation and bending moment of piston Pin. [8]

$$
\begin{gathered}
\sigma_{e b}=\frac{M \cdot y}{I \min } . F O S \ldots \ldots . \\
\sigma_{e b}=\frac{M \times d / 2}{\frac{\pi \mathrm{d}^{4}}{64}} \times 2 \\
d=\mathbf{x} \text { ' } \mathbf{m m} .
\end{gathered}
$$

Min. required small end ID of connecting rod subjected to crushing, $\mathrm{d}=\mathbf{x}$ " $\mathbf{m m}$.

Select max diameter out of $\mathrm{x}, \mathrm{x}^{\prime}$ and $\mathrm{x}$ "

\subsection{Small End thickness design:}

As the loads on Pin are completely reversed type, so considering S-N curve for infinity of life.

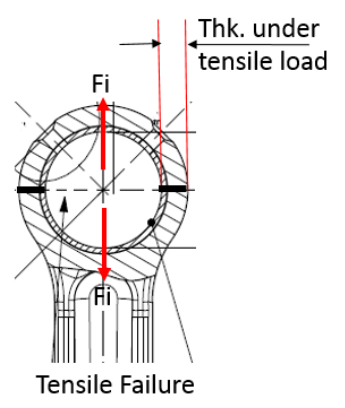

Figure 6. Tensile loading on connecting rod Small end.

Considering S-N curve for infinity of life

Thickness in Tensile loading

$$
\begin{aligned}
& \mathrm{Se}=\frac{\mathrm{F}_{\mathrm{i}} \cdot \mathrm{FOS}}{\mathrm{A}} \\
& \left.=\frac{\mathrm{F}_{\mathrm{i}} \cdot \mathrm{FOS}}{2 \times(l \times t)} \quad \text { (l=to be assumed }\right) \\
& \mathrm{t}=\mathrm{y} \mathbf{m m}
\end{aligned}
$$

Min required thickness of small end when subjected to tensile force, $\mathrm{t}=\mathrm{y} \mathrm{mm}$.

Thickness in Shear loading (Van mosses):

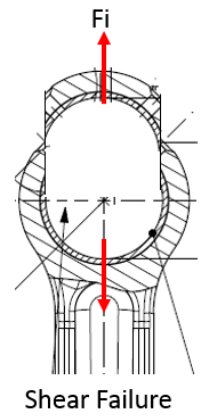

Figure7. Shearing of connecting rod Small end 
International Journal of Engineering Applied Sciences and Technology, 2020

Vol. 4, Issue 10, ISSN No. 2455-2143, Pages 116-121

Published Online February 2020 in IJEAST (http://www.ijeast.com)

$$
\begin{gathered}
\text { Ses }=\frac{\mathrm{F}_{\mathrm{i}} \cdot \mathrm{FOS}}{\mathrm{A}} \\
=\frac{\mathrm{F}_{\mathrm{i}} \cdot \mathrm{FOS}}{2 \times(l \times t)} \quad(l=\text { to be assumed. }) \\
\mathrm{t}=\mathbf{y} \text { ' } \mathbf{m m}
\end{gathered}
$$

Min required thickness of small end when subjected to Shear force, $\mathrm{t}=\mathrm{y}^{\prime} \mathrm{mm}$.

Select max value out of $\mathrm{t}$ from $\mathrm{y}$ and $\mathrm{y}$ ' for small end thickness. 2.9 Design of Bolt:

Table 5. Material Properties of bolt - $16 \mathrm{MnCr} 5$.

\begin{tabular}{|c|l|r|c|}
\hline S.N & \multicolumn{1}{|c|}{ Parameter } & Value & Unit \\
\hline 1 & Ultimate tensile Strength (SUT) & 570 & $\mathrm{Mpa}$ \\
\hline 2 & Yield tensile Strength (Syt) & 295 & $\mathrm{Mpa}$ \\
\hline 3 & Young's Modulus & 200000 & $\mathrm{Mpa}$ \\
\hline 4 & $\begin{array}{l}\text { Endurance Strength-Material (Von } \\
\text { Mises theory) (Se') }\end{array}$ & 285 & $\mathrm{Mpa}$ \\
\hline 5 & $\begin{array}{l}\text { Endurance Strength-Bolt (Se) } \\
\text { (Ka.Kb.Kc,Ke,Kf-1 \& Kd=1.05) }\end{array}$ & 290 & $\mathrm{Mpa}$ \\
\hline
\end{tabular}

Table 5. Material Properties of bolt - $16 \mathrm{MnCr} 5$

Bolt CS area in tensile stress,

Considering S-N curve for infinity life of Bolt

$$
\begin{aligned}
\mathrm{Se} & =\frac{\mathrm{F}_{\mathrm{i}} \cdot \mathrm{FOS}}{\mathrm{A} \times \text { No of Bolts }} \\
\mathrm{A} & =\mathrm{A} \mathrm{mm}^{2} \\
\mathrm{~d} & =\sqrt{\frac{A \times 4}{\pi}} \\
\mathrm{d} & =\mathrm{x} \mathrm{mm}
\end{aligned}
$$

Minor diameter of bolt $=\mathrm{d}=\mathrm{x} \mathrm{mm}$.

\section{Bolt Design as per IS:1367:}

Impact Tensile load on each bolt $=\frac{2 \times \text { Fi } \times \text { FOS }}{\text { No of bolts }} \mathbf{N}$

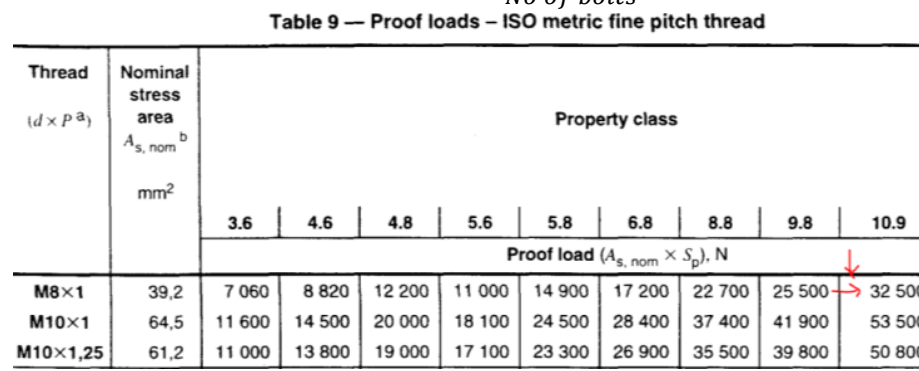

Table 6. Bolt selection as per IS:1367

Suitable Bolt Size can be selected from IS: 1367 based on the calculated tensile load.

Selecting max bolt size out of 3.6.1 and 3.6.2.

\section{EXPERIMENT AND RESULT}

$\mathrm{H}$ or I section dimensions, gudgeon pin diameter, outer diameter of small end and big end, bolt size can be finalized using above calculations.

Newly built 3D model is analyzed through FEA simulations and proved the all critical areas are with in limit of allowable stress. Kumar PraKash Shankar el al. (2015) [10], Mohammed M. N el al. (2012) [11] and Rehman ek al.(2008) addressed the FEA for connectind rod is their work.

Additionally, This Calculation Methodology is applied on connecting rods of different categories of state of the art productionised engines (Passengers, commercial and two wheeler engines.) And it is found that this methodology works properly with in FOS 2.

Structure behavior of connecting rod is checked through FEA for fatigue analysis using Tool - PTC Creo-Simulation. Meshing of connecting rod:

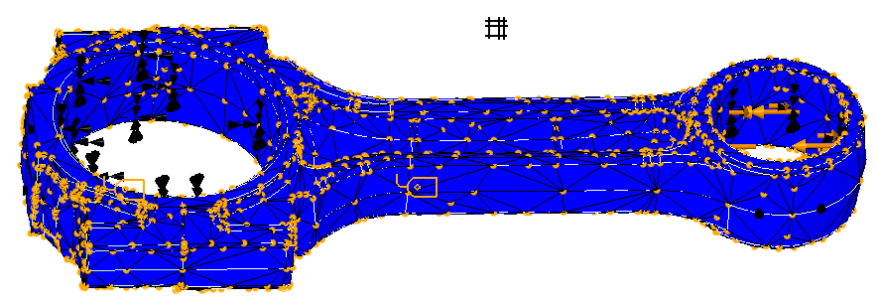

Figure8. Meshing of Connecting rod.

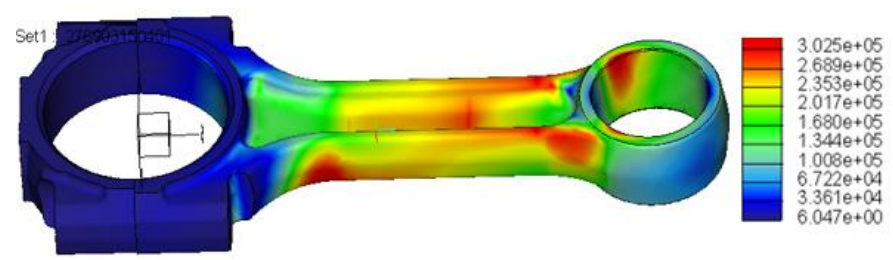

Figure 9. Stresse in KPa.

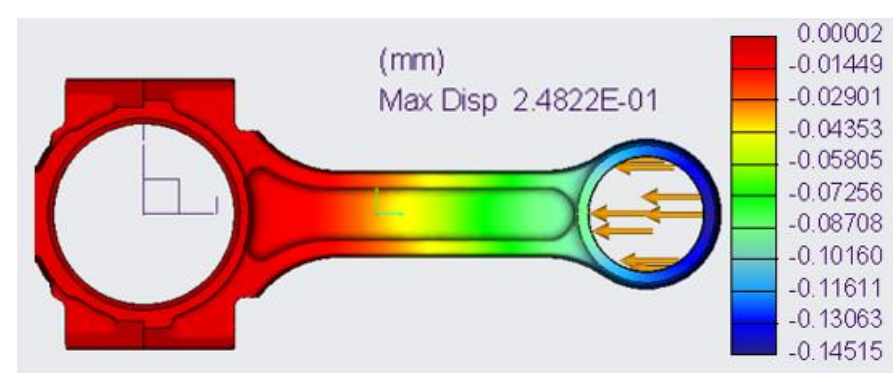

Figure 10. Deformation in compressive force. 


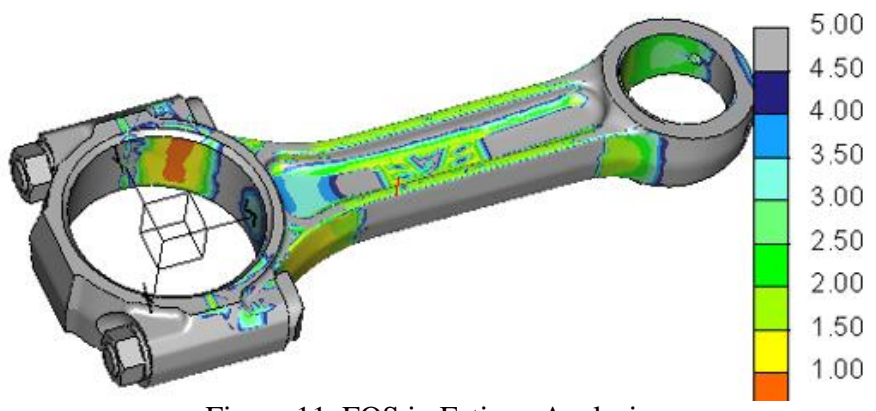

Figure 11. FOS in Fatigue Analysis.

\section{CONCLUSION}

It clearly shows that using above methodology and calculations, con rod can be designed or optimised within FOS as low as 2. It is verified using FEA analysis for fatigue failure as well as it is cross checked with connecting rod of actual working engines of different class from light to heavy four and two wheeler Engines. It resulted in weight reduction up to $10-15 \%$. Even Log Life (infinity life) remains above $\log$ of 6 .

\section{REFERENCE}

[1] Dr. Bansal R. K. (2009), "Strength of Materials- Columns and Struts", Laxmi Publications (Pvt) Ltd. Delhi, fourth edition, Pg. 810 - 870,.

[2] Kurmi R. S. and J. K. Gupta. (2005), "Theory of Machines - Balancing of reciprocating Masses", S. Chand \& Co. Ltd., New Dehli. Pg. 858-900.

[3] Bhandari V. B. (2010), "Design of Machine Elements", Mc Graw Hill Publications, $3^{\text {rd }}$ Edition.

[4] Singhal B. L. (2010), "Applied Thermodynamics", TecMax Publications, Pune.

[5] Shenoy P. S. and Fatemi A. (2006), "Dynamic analysis of loads and stress in connecting rod.", IMechE, Vol.220, Part C:J. Mechanical Engineering Science, DOI: 10.1243/09544062JMES105

[6] Haider Adnan Ali, Kuma Adnan Ali, Chowdhury Ajinkya, Khan Moin, Suresh P. (2018), "Design and structural Analysis of connecting rod", IRJET, Vol. 5 Issue:\% May20018 e-ISSN 23950056

[7] Ganeshan V. (2006), "Internal Combustion Engines Combustion and Combustion Chambers", Tata McGrawHill Publishing Company Ltd. New Delhi, 110020 ISBN 0-07-049457-6 Pg. 409-415.

[8] Ramamurti V., Sridhar S., Mithun S., Kumaravel B., Lavanya S. (2012), "Design considerations of Gudgeon pin in reciprocating air compressors by semi analytic approach". JMER, Vol 4 (3), DOI: 10.5897/JMER11.009 Pg 75-88.
[9] Vegi Leela Krishna, Vegi Venu Gopal, (2013), “Design and analysis of connecting rod using forged steel." IJSER, Vol.4, Issue 6, ISSN 2229-5518, Pg. 1-4

[10] Kumar Praksha Shankar, Kaushik Kumar. (2015), "Stress Analysis and Shape Optimazation of Connecting rod using differnet material.: Rest Journal of emering trends in modelling and Manufacturing, Vol. 1(20,2015, ISSn:24554537, Pg. 22-27.

[11] Mohammed M. N, Omar M.Z., Sajuri S., Salah A., Abdelgnei and Salleh M.S. (2012), "Failure Analysis of A Fractureng Rod", Journal of Asian Scientific Research. 2, Pg. 737-741.

[12] Rehman M. M, Ariffin A. K, Abdullah S., Noor M. M., Bakar R. A., and Maleque M. A. (2008), "Finite Element Based Fatigue Life Prediction of Cylinder Head for TwoStroke Linear Engine Using Stress-Life Approach," Journal of Applied Sciences. 8, 3316-3327

\section{ACKNOWLEDGMENT}

The author would like to thanks management of Tata Technologies Ltd. for allowing to work on this design methodology and for supporting to publish this technical literature. 